\title{
Historical Analysis of Bibliometric Trends in the Journal of Pediatric Orthopaedics With a Particular Focus on Sex
}

James P. Fischer; Austin E. Wininger; David C. Scofield; Aamir Tucker; Ethan J. Kacena-Merrell; Elizabeth C. Whipple; Melissa A. Kacena; Randall T. Loder

\begin{abstract}
Background: Orthopaedics is the clinical discipline with the lowest percentage of female residents and faculty. Pediatric orthopaedics has a higher percentage of women than other orthopaedic subspecialties. It was the purpose of this study to examine bibliometric trends in the Journal of Pediatric Orthopaedics (JPO) with a specific focus on gender.

Methods: A bibliometeric analysis for the years 2015, 2005, 1995, 1985, 1981 was performed. The names of first and corresponding authors; corresponding author position; country of origin; number of institutions, countries, authors, printed pages, and references was tabulated. Author gender was identified for the first and corresponding authors using the "Baby Name Guesser" (http://www.gpeters.com/names/baby-names.php). A p $<0.05$ was considered significant.
\end{abstract}

Results: There were 746 publications; $68.7 \%$ were from North America. The average number of authors, corresponding author position, collaborating institutions, countries, and number of references increased, while the number of printed pages decreased. Asia had the greatest number of authors (4.4), with Australia/New Zealand the fewest (3.4). Gender was determined for $98.3 \%$ of the first authors and $98.5 \%$ of the corresponding authors. There was a significant increase in the number of female first authors over time $\left(5.9 \%\right.$ to $\left.25.6 \%, \mathrm{p}<10^{-6}\right)$, especially in Europe and North America. There were significant increase in the number of female corresponding authors over time $(5.8 \%$ to $17.6 \%, \mathrm{p}=0.000009)$. There was a significant trend to have a greater percentage of both female first and corresponding authors over time $(\mathrm{p}=0.0005)$ with a reverse trend for both male first and corresponding authors $\left(\mathrm{p}<10^{-6}\right)$.

Conclusions: The increasing number of authors is a well known phenomenon and JPO is no different. Scientific publication is needed for promotion and tenure at academic medical centers. In this study, we noted that the number of female first and corresponding authors in JPO has been steadily increasing. Hopefully this will continue resulting- This should result in more female pediatric orthopaedic surgeons in academic faculty positions.

This is the author's manuscript of the article published in final edited form as:

Fischer, J. P., Wininger, A. E., Scofield, D. C., Tucker, A., Kacena-Merrell, E. J., Whipple, E. C., ... Loder, R. T. (2018). Historical Analysis of Bibliometric Trends in the Journal of Pediatric Orthopaedics With a Particular Focus on Sex. Journal of Pediatric Orthopaedics, 38(3), e168. https://doi.org/10.1097/BPO.0000000000001124 
Academic institutions worldwide value manuscript publication for career development in the tenure and promotion process. The number of publications an author has is now a form of currency in the academic profession (1-6). Publications are used to gain admission to medical school and residency, achieve academic promotion, and to compete for funding and research grants. There has been an increase in authorship over time (1,7-11). This may reflect playing a numbers game to achieve promotion and tenure, or it may also reflect increasing collaboration amongst authors. Such collaboration can be at different institutions, even in other states, countries and continents. Interdisciplinary collaboration requires commitment to a definition of goals, but enables researchers to solve complex, modern, multifaceted issues. Although researchers are competing against one another for funding and the culture of science has traditionally been more guarded, tTechnology allows researchers to form relationships with mutual respect and trust, enabling collaboration.

There is a well known gender discrepancy in achievement of promotion and tenure in US academic medicine (1215). Medicine was traditionally a male dominated field but is now changing. The percentage of female medical students increased from $11 \%$ in 1980 to $47 \%$ in years $2013-2014(16,17)$. These general changes in medical school matriculation may not equally translate to the residency gender composition of residents enrolled in residency programs. While surgical specialties have seen an increase in the number of female residents, surgical percentages are still lower than the overall percentage of female residents (18). The percentage of female orthopaedic surgery residents increased from $0.61 \%$ in 1970 to $13.2 \%$ in 2010 , well below the percentage of all female residents in all medical careers at $46.1 \%(18-20)$. Many studies have examined why women may be underrepresented in orthopaedics. Postulated theories include 1) lack of musculoskeletal education, 2) unfamiliarity with the field, 3) lack of female mentors and 4) unpleasant experiences/gender sterotype (20-26). Across all US medical schools, orthopaedics is the clinical discipline with the lowest percentage of female residents $(18,27-29)$ and full-time female faculty $(17,26,30)$.

Pediatric orthopaedics has a higher percentage of women than other orthopaedic subspecialties. From 2010 to 2014 women accounted for $25 \%$ of all applicants to pediatric orthopaedic fellowships (31). Sharkey et. al. (32) noted that females comprised $20.9 \%$ of candidate and active members of the Pediatric Orthopaedic Society of North America (POSNA). However, female members presented abstracts at a lower rate than males, suggesting females might be experiencing "barriers to academic participation". It was the purpose of this study to examine all bibliometric trends in the Journal of Pediatric Orthopaedics (JPO) including number of authors, geographic origin of the study, with a specific focus on author gender.

\section{MATERIALS AND METHODS:}

\section{Data Collection Methodology}

An analysis of $J P O$ examining one year from each decade in addition to the first year of publication (2015, $2005,1995,1985,1981)$ was performed. Similar methodology regarding intermittent year selection been previously described and validated in bibliometric studies (11,33-36). Publication data was downloaded into EndNote X7 (Thomson Reuters, New York, NY, 2013) for review and then later into a Microsoft Excel (Redmond, WA, 2013) 
file. The names of first and corresponding authors; corresponding author position; country of origin (corresponding author) and state or province for publications from the USA or Canada; number of institutions, countries, authors, printed pages, and references was tabulated. Countries were grouped by regions. North America was designated as the United States of America and Canada; Mexico, Central America, and South America as Latin America; the European continent including Russia and Turkey as Europe; and Asia as all Asian countries beginning west of Turkey, including the Middle East and Israel. The other regions were Africa and Australia/New Zealand. Manuscripts without author's names and those that were not original research (eg. memorandums, meeting notes, and abstracts) were excluded. Electronically published articles that were not printed until the following year were also deleted. The number of times each publication was cited was analyzed as a proxy of research quality. Citation data was obtained from a Scopus search during August 2016. Since more recent publications have a lesser chance of being cited, the citation values were normalized by dividing the number of times cited by the age of the article on August 2016 ( 1 for 2015, 11 for 2005, 21 for 1995, and 31 for 1985, and 35 for 1981). We thus also tabulated the number of institutions and countries for each manuscript.

Author gender was identified for the first and corresponding authors using the method described by Mimouni et. al. (37). The author's first name was entered into the "Baby Name Guesser" at http://www.gpeters.com/names/baby-names.php; the gender and gender ratio that indicated the likelihood of a male/female result was obtained. A ratio above 3.0 was chosen as a correct gender (37). If the ratio was less than 3.0, a Google search was used to assign gender; if such a search could not ascertain the gender, it was excluded for any gender-based analyses.

We hypothesized that advancements in technology increases the speed and ease of communication over large distances and thus increases collaboration. As publications have become increasingly important at all stages of academic careers from medical school applications to obtaining grants and tenure, we anticipated that the number of co-authors listed on publications would also increase over time.

\section{Statistical Analysis}

Continuous data are reported as the mean \pm 1 standard deviation. Discrete data are reported as percentages. Analyses between groups of continuous data were performed using non-parametric tests due to the data not having normal distributions (Mann-Whitney U -2 groups; Kruskal-Wallis test -3 or more groups). Differences between groups of discrete data were analyzed by the Fisher's exact test $\left(2 \times 2\right.$ tables) and the Pearson's $\chi^{2}$ test (greater than $2 \times 2$ tables). Trends over time for categorical variables were assessed using the Cochran linear trend test. For all statistical analyses $\mathrm{p}<0.05$ was considered statistically significant. Statistical analyses were performed with Systat 10 software $^{\mathrm{TM}}$ (Chicago, IL, 2000).

\section{RESULTS}

There were 746 publications that met inclusion criteria; 53 from 1981, 138 from 1985, 137 from 1995, 152 from 2005, and 166 from 2015. The total percentage of publications by region was $68.7 \%$ from North America, 17.0\% from Europe, 9.9\% from Asia, and 3.1\% from Australia/New Zealand. This did not change over time ( $\square^{2}$ test, $\mathrm{p}=0.17$ ). The remaining $1.2 \%$ were from Africa and Latin America and excluded from analyses by region. Those from Asia came from Japan (28.1\%), Korea (25.0\%), and Israel (21.9\%). All other Asian countries 
contributed less than 5\%. For those from Australia or New Zealand, 70\% were from New Zealand and 30\% from Australia. Those from Europe came from the United Kingdom (18.1\%), Sweden (10.3\%), Turkey (9.5\%), Italy (6.9\%), France, Germany, Poland, and Portugal (6.0\% each), and Finland, Ireland, and Spain (5.2\% each). All other European countries contributed less than $5 \%$ of the publications. For North America, USA contributed $92.3 \%$ of publications and Canada 7.7\%. The corresponding authors located in New England and California, followed by Texas, Pennsylvania, and Ontario, had the greatest percentages of publications (15.6\% from California, $6.8 \%$ from Massachusetts, 8.3\% from New York, 7.3\% from Pennsylvania, and 5.6\% from Texas, Pennsylvania, and Ontario) (Figure 1). All other states/provinces contributed less than 5\%.

Over the time span studied, the average number of authors increased from 2.4 to 4.8 , corresponding author position increased from 1.2 to 2.6, number of collaborating institutions from 1.2 to 2.2 , number of countries from 1.0 to 1.1 , number of references from 17.6 to 23.0, while the number of printed pages decreased from 6.3 to 5.6 (Table 1). The number of normalized citations was 0.70 in 1981 , increased to 2.07 in 2005 , and then dropped to 1.08 in 2015.

Differences by region of origin were also noted (Table 2). Asia had the greatest number of authors at 4.4, followed by Europe, North America, and Australia/New Zealand with the fewest at 3.4. The corresponding author position was 1.9 for North America, Asia, and Australia/New Zealand, and 1.6 for Europe. Although the number of collaborating institutions did not differ significantly by region, there was a significant difference in the number of countries collaborating on each publication by region. Publications originating from Australia/New Zealand had the greatest number of countries collaborating at 1.3, while Europe, Asia, and North America all had 1.1 countries. There were no significant differences by region for the number of references, printed pages, or normalized citations.

The corresponding author position increased over time (Figure 2). In 1981, the corresponding author was first author $60 \%$ of the time and last author $9 \%$ of the time. There were $21 \%$ single author articles in 1981 . Similar numbers were seen for 1985, except that the number of single author articles decreased to $10 \%$. This trend continued until there were no single author articles in 2015. The percentage of corresponding authors as first authors remained constant at approximately $60 \%$ until 2015 when a decline to $53 \%$ was observed. The percentage of corresponding author as last author increased from $9 \%$ in 1981 to $38 \%$ in 2015.

Gender could be determined for $98.3 \%$ of the first authors and $98.5 \%$ of the corresponding authors. There was a significant increase in the number of female first authors over time $\left(\mathrm{p}<10^{-6}\right.$, Cochran linear trend, Figure $3 \mathrm{~A}) ; 5.9 \%$ in $1981,7.0 \% 1985,7.6 \%$ in $1995,13.5 \%$ in 2005 , and $25.6 \%$ in 2015 . There was a dramatic and significant increase in female first authors over time in Europe $(p=0.001$, Cochran linear trend) and North America $(p=0.00006$, Cochran linear trend), as the percentage of female first authors in Europe rose from $0 \%$ to $33.3 \%$, and in North America from 5.6\% to 23.9\%. There was no trend for Asia. The data for Australia/New Zealand was based on a small sample size and was not significant.

There were significant differences in the number of female corresponding authors over time $(p=0.000009$, Cochran linear trend) (Figure 3B), which increased from 5.8\% 1981 to $17.6 \%$ in 2015. When broken down by region, North America demonstrated an increase ( $\mathrm{p}=0.00004$, Cochran linear trend), with female corresponding authors going from $5.4 \%$ to $20.0 \%$, as well as Europe ( $\mathrm{p}=0.037$, Cochran linear trend), going from $0 \%$ to $12 \%$. 
The percentage of female corresponding authors changed over time in Asia $(\mathrm{p}=0.014)$, without a linear trend $(\mathrm{p}=$ 0.72). The data for Australia/New Zealand was again not interpretable based on a small sample size.

There was a significant trend to have a greater percentage of both female first and corresponding authors from 1981 to 2015 . The total percentage of publications with both female first and corresponding authors was $7.9 \%$, and went from 5.8\% in 1981 to $8.6 \%$ in 2015 ( $\mathrm{p}=0.0005$, Cochran linear trend). The trend was reversed for both male first and corresponding authors; the total percentage of publications with both male first and corresponding authors was $83.5 \%$, and went from $94.2 \%$ to $71.7 \%\left(\mathrm{p}<10^{-6}\right.$, Cochran linear trend). There was also a trend to have female first and male corresponding authors, going from $0 \%$ to $4.6 \%(\mathrm{p}=0.0005$, Cochran linear trend), as well as male first and female corresponding authors, going from $0 \%$ to $3.0 \%$ ( $\mathrm{p}=0.011$, Cochran linear trend).

\section{DISCUSSION}

This JPO bibliometric study has shown that the number of authors, institutions and countries has increased over time, while the number of printed pages has dropped. This drop likely represents a conscious effort to reduce the burden of weight, publication cost, and shipping expenses for the hard copy product. The increasing number of authors is a well known phenomenon in all of academic medicine $(1,7-11,35)$, and $J P O$ is no different. The correctness of this change is controversial, and is being debated at many levels $(10,38)$ as it may or may not reflect the increasing complexity of medical research $(9-11,38)$. Multi center studies allow for larger numbers with more robust data, analyses, and conclusions. Such methodology is an improvement from single center studies, and can explain, at least in part, the increasing number of authors, although this is being fervently debated $(9-11,38)$.

Orthopaedic surgery has traditionally been a male dominated field, although this is changing over time, but not commensurate with the number of female medical student matriculates or graduates (20-22). Pediatric orthopaedics has the highest percentage of applicants for fellowships compared to other orthopaedic subspecialties, as well as the highest rate of success in the match (31). This likely reflects the increasing number of female pediatric orthopaedic surgeons. In May 2017, the overall percentage of female North American POSNA members was $20.5 \%$ (248 of 1211); for senior members it was 3.5\% (8 of 227), active members $19.9 \%$ (140 of 705$)$, and candidate members $35.8 \%$ (100 of 279) (39). This clearly demonstrates that the number of women in pediatric orthopaedics is increasing over time.

There are potential limitations of this study. First, it was a sampling every decade. It is possible that the particular sample year happened to have a much different distribution of papers by the factors studied. However, we were looking for trends in this study, not absolute numbers. Our method has been validated by many other studies (11,33-36). Another limitation is that the gender was not found for all of the publications. However, the impact would be small since the gender was not identified in only 1.5 to $1.7 \%$ of the studies. Finally, there might be some errors in the assignment of the geographic region by using the corresponding author's location.

Scientific publication is needed for promotion and tenure at academic medical centers. Successful publication is the "true currency" for academic promotion (1-6). There is still a lag, however, in participation of females in abstract authorship at recent POSNA meetings (32). After abstract authorship, the next step is manuscript publication; here the gender gap has been ubiquitously described (40). In this study, we noted that the number of female first and corresponding authors in JPO has been steadily increasing. This has been noted globally but may 
be hitting a plateau (41). Hopefully, the trend will not plateau, but continue to have an increased number of female pediatric orthopaedic surgeons in academic faculty positions. 


\section{REFERENCES}

1. Camp M, Escott BG. Authorship proliferation in the orthopaedic literature. J Bone Joint Surg [Am] 2013;95-A:e44(1-5).

2. Tornetta 3rd P, Siegel J, McKay P, Bhandari M. Authorship and ethical considerations in the conduct of observational studies. J Bone Joint Surg [Am] 2009;Supp 3:61-67.

3. Thomas PA, Diener-West M, Canto MI, Martin DR, Post WS, Streiff MB. Results of an academic promotion and career path survey of faculty at the Johns Hopkins University School of Medicine. Acad Med 2004;79:258-264.

4. $\quad$ Lundberg GD. Writing is all. Lancet 1998;352:898.

5. Fleming VM, Schindler N, Martin GJ, DaRosa DA. Separate and equitable promotion tracks for clinicianeducators. JAMA 2005;294:1101-1104.

6. Ence AK, Cope SR, Holliday EB, Somerson JS. Publication productivity and experience: factors associated with academic ranks among orthopaedic surgery faculty in the United States. J Bone Joint Surg [Am] 2016;98-A:e41(1-6).

7. PubMed. Number of authors per MEDLINE® /PubMed® citation. https://www.nlm.nih.gov/bsd/authors1.html. Accessed June 4, 2017.

8. Aboukhalil R. The rising trend in authorship. The Winnower 2014;2:e141832.26907.

9. Weeks WB, Wallace AE, Kimberly BCS. Changes in authorship patterns in prestigious US medical journals. Soc Sci Med 2004;59:1949-1954.

10. Papatheodorou SI, Trikalinos TA, Ioannidis JPA. Inflated numbers of authors over time have not been just due to increasing research complexity. J Clin Epidemiol 2008;61:546-551.

11. Tilak G, Prasad V, Jena AB. Authorship inflation in medical publications. Inquiry 2015;52.

12. Tesch BJ, Wood HM, Helwig AL, Nattinger AB. Promotion of women physicians in academic medicine. Glass ceiling or sticky floor? JAMA 1995;273:1022-1025.

13. Wright AL, Schwindt LA, Bassford TL, Reyna VF, Shisslak CM, St. Germain PA, et al. Gender differences in academic advancement: patterns, causes, and potential solutions in one US College of Medicine. Acad Med 2003;78:500-508.

14. Zhuge Y, Kaufman J, Simeone DM, Chen H, Velazquez OC. Is there still a glass ceiling for women in academic surgery? Ann Surg 2011;253:637-643.

15. Sexton KW, Hocking KM, Wise E, Osgood MJ, Cheung-Flynn J, Komalavilas P, et al. Women in academic surgery: the pipeline is busted. J Surg Educ 2012;69:84-90.

16. Group on Women in Medicine and Science. 2013-2014 Data Tables, Table 1: Medical Students, Selected Years 1965-2013 [Association of American Medical Colleges Web Site]. 2014.

https://www.aamc.org/members/gwims/statistics/. Accessed June 1, 2017.

17. Lautenberger DM, Dandar VM, Raezer CL, Sloane RA. The State of Women in Academic Medicine. The Pipeline and Pathways to Leadership. 2014. https://members.aamc.org/eweb/upload/The-state of f-Women-inAcademic-Medicine-2013-2014-FINAL.pdf. Accessed December 18, 2016. 
18. Blakemore LC, Hall JM, Biermann JS. Women in surgical residency training programs. J Bone Joint Surg [Am] 2003;85-A:2477-2480.

19. Association of American Medical Colleges, Center for Workforce Studies, Erikson C, Jones K, Tilton C. 2012 Physician Specialty Data Book.

https://www.aamc.org/download/313228/data/2012physicianspecialtydatabook.pdf. Accessed December 18, 2016.

20. Miller EK, LaPorte DM. Barriers to women entering the field of orthopaedic surgery. Orthopedics 2015;38:530-533.

21. Lewis VO, Scherl SA, O'Connor ML. Women in orthopedics-way behind the number curve. J Bone Joint Surg [Am] 2012;94:e30.

22. Schroeder JE, Zisk-Rony RY, Liebergall M, Tandeter H, Kaplan L, Weiss YG, et al. Medical students' and interns' interest in orthopedic surgery: the gender factor. J Surg Educ 2014;71:198-204.

23. Bucknall V, Pynsent PB. Sex and the orthopaedic surgeon: a survey of patient, medical student and male orthopaedic surgeon attitudes towards female orthopaedic surgeons. Surgeon 2009;7:89-95.

24. Stratton TD, McLaughlin MA, Witte FM, Fosson SE, Nora LM. Does students' exposure to gender discrimination and sexual harassment in medical school affect specialty choice and residency program selection? Acad Med 2005;80:400-408.

25. O'Connor MI. Medical school experiences shape women students' interest in orthopaedic surgery. Clin Orthop 2016;474:1967-1972.

26. Hill Jf, Johnson AH, Cannada L. A profile of female academic orthopaedic surgeons. Curr Orthop Pract 2013;24:636-640.

27. Rohde RS, Wolf JM, Adams JE. Where are the women in orthopaedic surgery? Clin Orthop 2016;474:1950-1956.

28. Templeton $\mathrm{K}$, Wood VJ, Haynes R. Women and minorties in orthopedic residency programs. JAAOS 2007;15:S37-S41.

29. Van Heest AE, Agel J. The uneven distribution of women in orthopaedic surgery resident training programs in the United States. J Bone Joint Surg [Am] 2012;94-A:e9-1-8).

30. Jena AB, Khullar D, Ho O, Olenski AR, Blumenthal DM. Sex differences in academic rank in US medical schools in 2014. JAMA 2015;314:1149-1158.

31. Cannada LK. Women in orthopaedic fellowships: what is their match rate, and what specialties do they choose? Clin Orthop 2016;474:1957-1961.

32. Sharkey MS, Feinn RS, Tate VV, Carter CW, Cassese TT. Disproportianate participation of males and females in academic pediatric orthopaedics: an analysis of abstract authorship at POSNA 2009-2013. J Pediatr Orthop 2016;36:433-436.

33. Hettrich CM, Hammoud S, LaMont LE, Arendt EA, Hannafin JA. Sex-specific analysis of data in highimpact orthopaedic journals: how are we doing? Clin Orthop 2015;473:3700-3704. 
34. Piper CL, Scheel JR, Lee CI, Forman HP. Gender trends in radiology authorship: a 35-year analysis. AJR 2016;206:3-7.

35. Baek S, Yoon DY, Cho YK, Yun EJ, Seo YL, Lim KJ, et al. Trend toward an increase in authorship for leading radiology journals. AJR 2015;205:924-928.

36. Lehman JD, Schairer WW, Gu A, Blevins JL, Sculco PK. Authorship trends in 30 years of the Journal of Arthroplasty. J Arthroplasty 2017;32:1684-1687.

37. Mimouni M, Zayit-Soudry S, Segal O, Barak Y, Nemer AY, Shylman S, et al. Trends in authorship of articles in major ophthalmology journals by gender. Ophthalmology 2016;123:1824-1828.

38. Reich MS, Shaw J, Barrett L, Goldberg VM, Schnaser E. Level of evidence trends in the Journal of Bone and Joint Surgery, 1980-2010. Iowa Orthop J 2014;34:197-203.

39. Raymond M. POSNA membership. In:; 2017.

40. Jagsi R, Guancial EA, Worobey CC, Henault LE, Chang Y, Starr R, et al. The "gender gap" in authorship of academic medical literature - a 35-year perspective. N Engl J Med 2006;355:281-287.

41. Filardo G, da Graca B, Sass DM, Pollock BD, Smith EB, Martinez MA-M. Trends and comparison of female first authorship in high impact medical journals: observational study (1994-2014). BMJ 2016;352:i847. 


\section{FIGURE LEGENDS}

Figure 1. Origin of manuscripts from North America. Darker shading represents a higher percentage of manuscripts from that state/province, with white no manuscripts from that state/province.

Figure 2. Percentage of corresponding authors by position.

\section{Figure 3.}

A. Gender distribution of first authors over time by region.

B. Gender distribution of corresponding authors over time by region. 